\title{
Induction of apoptosis in A549 pulmonary cells by two Paracoccidioides brasiliensis samples
}

\author{
Adriana Del Vecchio', Julhiany de Fatima da Silva', Juliana Leal Monteiro da Silva', \\ Patricia Ferrari Andreotti ${ }^{1}$, Christiane Pienna Soares ${ }^{1}$, Gil Benard ${ }^{2,3}$, \\ Maria José Soares Mendes Giannini ${ }^{1 /+}$
}

\begin{abstract}
1Departamento de Análises Clínicas, Faculdade de Ciências Farmacêuticas, Universidade Estadual Paulista, R. Expedicionários do Brasil 1621, 14801-902 Araraquara, SP, Brasil ²Laboratório de Investigação Médica (LIM)-53, Instituto de Medicina Tropical ${ }^{3}$ LIM-56, Divisão de Clínica Dermatológica, Hospital das Clínicas, Faculdade de Medicina, Universidade de São Paulo, São Paulo, SP, Brasil
\end{abstract}

Paracoccidioidomycosis presents a variety of clinical manifestations and Paracoccidioides brasiliensis can reach many tissues, most importantly the lungs. The ability of the pathogen to interact with host surface structures is essential to its virulence. The interaction between P. brasiliensis and epithelial cells has been studied, with particular emphasis on the induction of apoptosis. To investigate the expression of different apoptosis-inducing pathways in human A549 cells, we infected these cells with P. brasiliensis Pb18SP (subcultured) and 18R (recently isolated from cell culture and showing a high adhesion pattern) samples in vitro. The expressions of Bcl-2, Bak and caspase 3 were analysed by flow cytometry and DNA fragmentation using the TUNEL technique. Apoptosis of human A549 cells was induced by $\mathrm{P}$. brasiliensis in a sample and time-dependent manner. Using an in vitro model, our data demonstrates that caspase 3, Bak, Bcl-2 and DNA fragmentation mediate P. brasiliensis-induced apoptosis in A549 cells. The overall mechanism is a complex process, which may involve several signal transduction pathways. These findings could partially explain the efficient behaviour of this fungus in promoting tissue infection and/or blood dissemination.

Key words: apoptosis - Paracoccidioides brasiliensis - caspase 3 - Bak - Bcl-2

Paracoccidioidomycosis (PCM) is associated with several clinical manifestations and can reach the lungs, where it is primarily found, as well as many other tissues. Paracoccidioides brasiliensis isolates vary in virulence and this variability may influence the host-parasite relationship (Franco et al. 1994). On the other hand, their virulence can be attenuated or lost during consecutive cycles of subculturing over long periods (Brummer et al. 1990) but re-established after inoculating into animals (Castaneda et al. 1987, San-Blas et al. 1977) or after passing through cell culture (Andreotti et al. 2005).

$P$. brasiliensis $(\mathrm{Pb})$ yeast cells can enter different types of cells and probably manipulate the host cell environment to benefit their own growth and survival (Mendes-Giannini et al. 2004). The successive events that may occur with $P$. brasiliensis are fungal adhesion, translocation into the cell cytoplasm, multiplication and the induction of apoptosis. The correlation between pathogenic mechanisms in vivo could elucidate the initial steps of the infection (Mendes Giannini et al. 2000, 2004). The death of cells with internalised $P$. brasiliensis yeast cells could allow the yeast to disseminate to distant sites, such as the metastatic focus. The fungus is not a simple clone with a constant phenotype; inter and intra-variations tend to occur (Macoris et al.

Financial support: FAPESP, CNPq, CAPES

+ Corresponding author: giannini@fcfar.unesp.br

Received 1 September 2008

Accepted 4 June 2009
2006). Elucidation of the interaction between $P$. brasiliensis and epithelial or alveolar cells has contributed to a better understanding of the mechanisms of adherence and their involvement in the virulence of this fungus. Several studies have demonstrated the ability of $P$. brasiliensis to adhere to and invade cells (Mendes-Giannini et al. 1994, 2008, Monteiro da Silva et al. 2007) and the adhesion varies depending on the isolate studied (Hanna et al. 2000). Pathogen entry into host cells is initiated by the fungus gaining access to the cell surface, which then generates signals to induce internalization of the fungus. This strictly regulated process is a genetically and biochemically programmed cell death that is critical during development and tissue homeostasis and is associated with the pathogenesis of several diseases (Thompson 1995). A number of pathogens cause host cell death with apoptotic features (Moss et al. 1999). Previous studies have investigated the induction of apoptosis in P. brasiliensis-infected cells (Souto et al. 2003, MendesGiannini et al. 2005, Verícimo et al. 2006, Silva et al. 2008), but no study has compared P. brasiliensis samples to show the correlation of adhesion with the induction of apoptosis. Cacere et al. (2002) suggested that in PCM patients, apoptosis plays a role in the antigen-specific hyporesponsiveness of $\mathrm{T}$ cells to the main antigen of $P$. brasiliensis, the $43-\mathrm{kDa}$ glycoprotein. The ability of pathogens to induce apoptosis in phagocytes might be an important factor in virulence, as it would curtail the host's defence mechanisms. P. brasiliensis and other fungi can use phagocyte apoptosis to their own advantage, as it allows their intracellular survival in epithelial cells, which could potentially elicit this type of cell 
death. Campanelli et al. 2003 also showed that apoptosis mediated by Fas-FasL and the engagement of CTLA-4 is involved in the modulation of the immune response in patients infected with this fungus.

Programmed cell death is also regulated by extracellular signals, which can activate or inhibit apoptosis. There are two distinct biochemical mechanisms that initiate classical apoptosis: (i) the extrinsic pathway, involving cell surface death receptors binding to their ligands and (ii) the intrinsic mitochondrial pathway, which is primarily controlled by pro and anti-apoptotic proteins of the Bcl-2 family. Both of these pathways activate caspases (Perksuist et al. 2002). It is well known that the expression of many proteins, such as Bak and Bcl-2, is very important in the course of programmed cell death. Bcl-2, BclXL and Bcl-1 exhibit anti-apoptotic functions, whereas Bak, Bax, Bim and BclXS promote apoptosis. The balance between these two groups determines the destiny of cells in many systems (Perskvist et al. 2002). In mammals, apoptosis can be activated by caspases, which cleave specific substrates and trigger cell death. These signalling molecules mainly regulate the levels and activities of Bcl-2 family members, which consist of anti-apoptotic factors, such as Bcl-2 and proapoptotic proteins, such as Bak (Adams \& Cory 1998). Hence, $\mathrm{Bcl}-2$ proteins impair apoptosis by preventing the release of mitochondrial interspace proteins, including cytochrome $\mathrm{c}$ and the apoptosis-inducing factor, whereas Bak stimulates the release of cytochrome $\mathrm{c}$ from the mitochondria, thus resulting in apoptosis (Shimizu et al. 1999). Bcl-2 and cytochrome c release are normally associated with caspase activation (Cosulich et al. 1999).

The mechanisms of $P$. brasiliensis invasion into host cells, their persistence and the subsequent induction of apoptosis may explain their ability to disseminate (Mendes Giannini et al. 2004). However, the apoptotic mechanisms in alveolar epithelial cells remain largely unexplored. Thus, we investigated whether the pattern of $P$. brasiliensis infection in epithelial cells could be associated with host cell apoptosis.

\section{MATERIALS AND METHODS}

Microrganism - Strain 18 of P. brasiliensis ( $\mathrm{Pb} 18)$ was grown in Fava-Netto's medium at $35^{\circ} \mathrm{C}$ and subcultured 72 times, 3-4 days each time, to yield the sample $\mathrm{Pb} 18 \mathrm{SP}$. Pb18 was reisolated after five consecutive passages through cultured cells and the resulting sample was called Pb18R.

Epithelial cells - Cultures of A549 cells, a human lung adenocarcinoma cell line, were obtained from the American Type Culture Collection (Rockville, MD). These cells were cultured in Ham's F-12 medium supplemented with $10 \%$ heat inactivated fetal calf serum.

Infection assay - A549 cells were cultured at $36.5^{\circ} \mathrm{C}$ in 6-well plates and adjusted to $3.0 \times 10^{4}$ cells per well. Then, $1.0 \times 10^{6}$ yeast forms $/ \mathrm{mL}$ of each sample (Pb18SP and $\mathrm{Pb} 18 \mathrm{R}$ ) previously labelled with carboxyfluorescein diacetate succinimidyl ester were added to the cells (Lyons AB, Parish, 1994) and incubated for 2, 5, 18, 24 and $48 \mathrm{~h}$ at $36.5^{\circ} \mathrm{C}$, in order to observe the total percentage of infection. After these periods, the cells were washed, removed from the 6-well plates using a trypsin-ATV solution, fixed with $4 \%$ paraformaldehyde and analysed using BD FACSCanto (Becton Dickinson Immunocytometry System, San Jose, California, USA) and FACS-Diva software.

Apoptosis assays - TUNEL technique - The terminal deoxyribonucleotidyl transferase-mediated triphosphate (dUTP)-biotin nick end labelling (TUNEL) and Gavrieli method were used to detect DNA fragmentation of nuclei (Gavrieli et al. 1992). Epithelial cells were grown on glass coverslips and incubated for 5, 24 and $48 \mathrm{~h}$ with $1.0 \times 10^{6}$ yeast forms $/ \mathrm{mL}$ of each sample (Pb18SP and $\mathrm{Pb} 18 \mathrm{R})$. After these periods, the coverslips were washed and fixed. The coverslips were blocked with bovine serum albumin, permeabilised and incubated with terminal D-transferase and fluorescent dUTP (Boehringer Mannheim). Apoptotic bodies were revealed by fluorescence microscopy (Microscopic DMLB Leica with DFC300FX) using the Leica Image Manager 50 software. In addition, the same procedure was performed to quantify apoptotic cells, using flow cytometry according to the manufacturer's recommendations.

Flow cytometry - Bcl-2 and Bak - Epithelial cells were grown in 6-well plates to confluence and incubated with $1.0 \times 10^{6}$ yeast forms $/ \mathrm{mL}$ of each of the sample (Pb18SP and Pb18R) for 5, 18 and $24 \mathrm{~h}$, in order to study $\mathrm{Bcl}-2$ and Bak expression. For the flow cytometric assay, after incubation, the cells were washed, trypsinised and fixed with $4 \%$ paraformaldehyde. The reaction was performed using monoclonal antibodies diluted 1:100 (Bak) and 1:100 (Bcl-2) in PBS with 0.5\% saponine. Following the primary antibodies, 1:50 phycoeritrin-conjugated secondary antibodies were added and, after infection with $P$. brasiliensis, the apoptotic cells were quantified by flow cytometry. As a positive control, epithelial cells were treated with Methotrexate $1 \mu \mathrm{M}$ for $24 \mathrm{~h}$. As a negative control, untreated cells were also evaluated to determine the basal $\mathrm{Bcl}-2$ and Bak expression.

Flow cytometry - caspase 3 - Epithelial cells were grown to confluence in 6-well plates and incubated with $1.0 \times 10^{6}$ yeast forms $/ \mathrm{mL}$ of each of the sample (Pb18SP and Pb18R) for 5, 18, 24 and $48 \mathrm{~h}$ to study the activation of caspase 3. After incubation, the cells were washed, trypsinised and fixed with $4 \%$ paraformaldehyde. The assay was performed using caspase 3 monoclonal antibodies diluted to $1: 100$ in PBS with $0.5 \%$ saponin, followed by 1:50 of phycoeritrin-conjugated secondary antibodies. Apoptosis of P. brasiliensis-infected cells was quantified using flow cytometry.

Statistics - Data from three independent repeated experiments were analysed by the Student's $t$ test.

\section{RESULTS}

Pulmonary epithelial cell infection assay - First, we verified that A549 cells were infected with $P$. brasiliensis by flow cytometric analysis. A time course of infection was carried out from 2-48 h of contact with both Pb18SP and $\mathrm{Pb} 18 \mathrm{R}$, the subcultured and reisolated samples, re- 
spectively. P. brasiliensis yeast cells of both types were observed inside the A549 cells after $5 \mathrm{~h}$ of infection (data not shown). Quantification of yeast cells revealed significant differences between $\mathrm{Pb} 18 \mathrm{SP}$ e Pb18R in relation to the time of infection, mainly at 2, 18 and $24 \mathrm{~h}$ (Fig. 1) because after $5 \mathrm{~h}$ of infection internalisation has begun and a decrease in infection was observed. Pb18R was able to infect A549 cells more efficiently than Pb18SP.

Apoptosis assay - TUNEL technique - Using TUNEL staining, we investigated nuclear DNA fragmentation in infected A549 cells as a possible mechanism of P. brasiliensis-induced cell death. Yeast forms of $P$. brasiliensis in apoptotic cells were observed after 5, 24 and $48 \mathrm{~h}$ of incubation (Fig. 2). Initial apoptotic DNA fragments were observed by fluorescence microscopy as well as by flow cytometry in infected cells, but not uninfected cells (Fig. 2A, B). Pb18R-infected A549 cells showed significantly more nuclear DNA fragmentation than Pb18SP-infected cells, mainly at the $48 \mathrm{~h}$ time point (data not show). The fragmentation also increased with the incubation time.

Bcl-2 and Bak - The expression of Bak and Bcl-2 was measured by flow cytometry. Fig. 3 shows the results from cells infected with Pb18SP and Pb18R for different periods of time. At an early time during the infection (5 h), the expression of Bak and Bcl-2 was higher in infected cells when compared to the uninfected cells. Bak expression was significantly increased in cells infected with Pb18R as compared to cells infected with Pb18SP $(p<0.0001)$. In addition, $\mathrm{Bcl} 2$ expression was twice as high in cells infected with $\mathrm{Pb} 18 \mathrm{R}$ than in cells infected with Pb18SP ( $p<0.0001)$. After $18 \mathrm{~h}$ of infection, Bak expression also showed a significant difference between cells infected with Pb18SP and $\mathrm{Pb} 18 \mathrm{R}$, demonstrating at least a three-fold increase in expression in cells infected with $\mathrm{Pb} 18 \mathrm{R}$ as compared to Pb18SP. Bcl-2 expression was dramatically decreased (less than 1\%) in cells infected with Pb18SP, whereas in Pb18R-infected cells we were able to detect at least 4\%

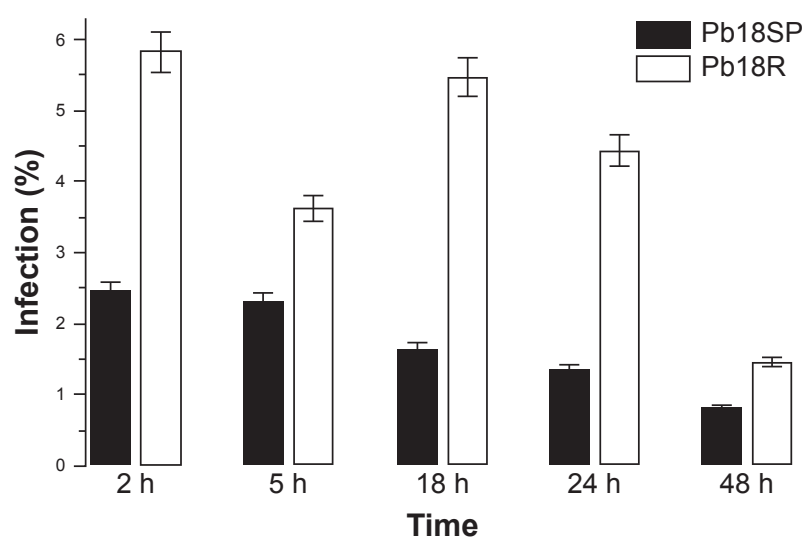

Fig. 1: percentage of A549 cells showing yeast infection plotted against time of incubation (hours) with two samples of Paracoccidioides brasiliensis strain 18, one subcultured in vitro (Pb18SP) and the other reisolated from cell culture (Pb18R). Data represent means and standard deviations of three independent experiments. of Bcl-2 expression ( $\mathrm{p}<0.05)$. At a later point of infection (24 h) Bcl-2 expression fell below the basal levels in cells infected with either strain. In contrast to Bak expression, we did not observe a significant difference between infected cells and the controls.

Flow cytometry - Caspase 3 - Caspase activation is essential for DNA fragmentation during apoptosis induced by a variety of stimuli. We therefore measured the activity of caspase 3 in P. brasiliensis-infected A549 cells by flow cytometry. Fig. 4 shows the results of infections with $\mathrm{Pb} 18 \mathrm{SP}$ and $\mathrm{Pb} 18 \mathrm{R}$ for different periods of time. A549 cells infected with Pb18R only showed a significant level of caspase 3 expression after $48 \mathrm{~h}$ of infection $(\mathrm{p}<0.05)$. At $5 \mathrm{~h}$, the expression of caspase 3 was the same in cells infected with either Pb18SP or $\mathrm{Pb} 18 \mathrm{R}$. However, the difference was much more evident in cells infected with Pb18R at $48 \mathrm{~h}(\mathrm{p}<0.05)$ and after $48 \mathrm{~h}$ (data not show).
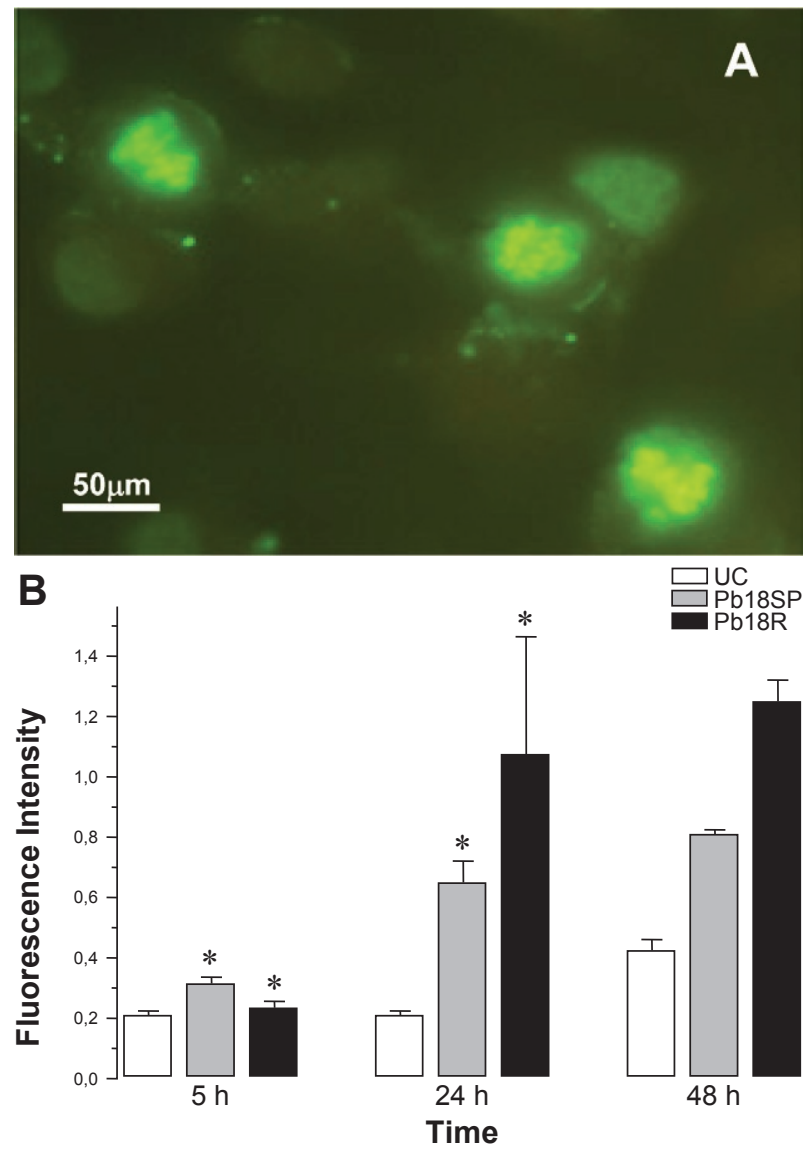

Fig. 2: Paracoccidioides brasiliensis-induced apoptosis in A549 cells. A549 cells were cultured without or with $P$. brasiliensis and analysed by in situ TUNEL technique (A) infected with P. brasiliensis demonstrating the DNA fragmentation and apoptotic bodies by fluorescence microscopy (1000X). B: flow cytometric analysis was also performed by TUNEL technique as described in the methods section and the data shown are representative of three separate experiments; Pb18SP: strain 18 of $P$. brasiliensis; Pb18R: strain 18 of $P$. brasiliensis recently isolated from cell culture; UC: uninfected cells. Asterisks means no significant. Values given are mean \pm standard deviation $(p<0.05)$ of three independent experiments. 

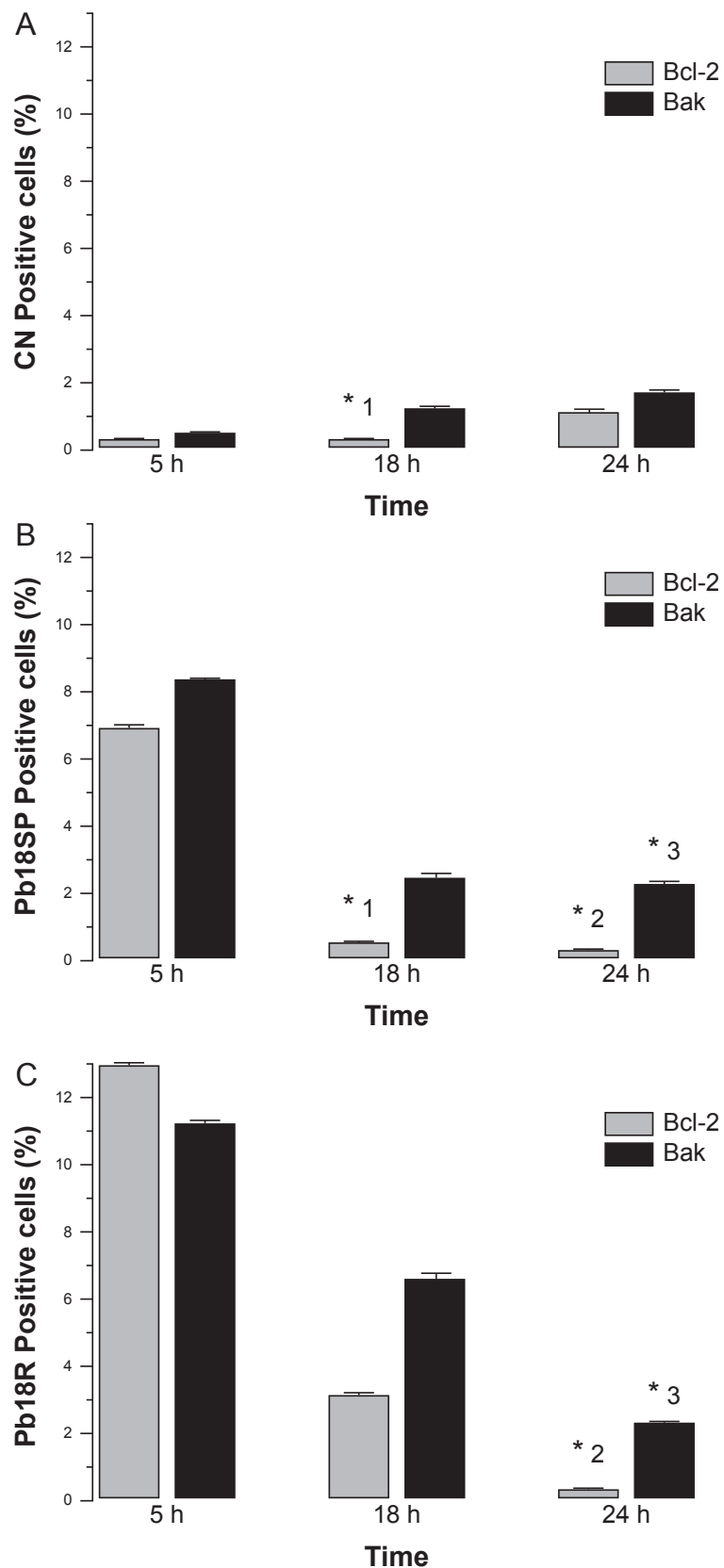

Fig. 3: the expression of Bak and Bcl-2 protein in A549 cells. Following treatment with Paracoccidioides brasiliensis for the time periods indicate, cells were collected. Bak and Bcl-2 proteins were detected by flow cytometry. A: UC positive cells; B: positive cells infected with strain 18 of $P$. brasiliensis (Pb18SP); C: positive cells infected with strain 18 of $P$. brasiliensis recently isolated from cell culture (Pb18R). Asterisks means no significant in these indicated conditions. Values given are mean \pm standard deviation $(\mathrm{p}<0.05)$ of three independent experiments.

\section{DISCUSSION}

The mechanisms of $P$. brasiliensis virulence are not completely understood. There is a consensus that successive subculturing of this fungus causes a loss of pathogenicity that can be reversed by reisolating the fungus after passage in animals or in epithelial cells in vitro, thereby

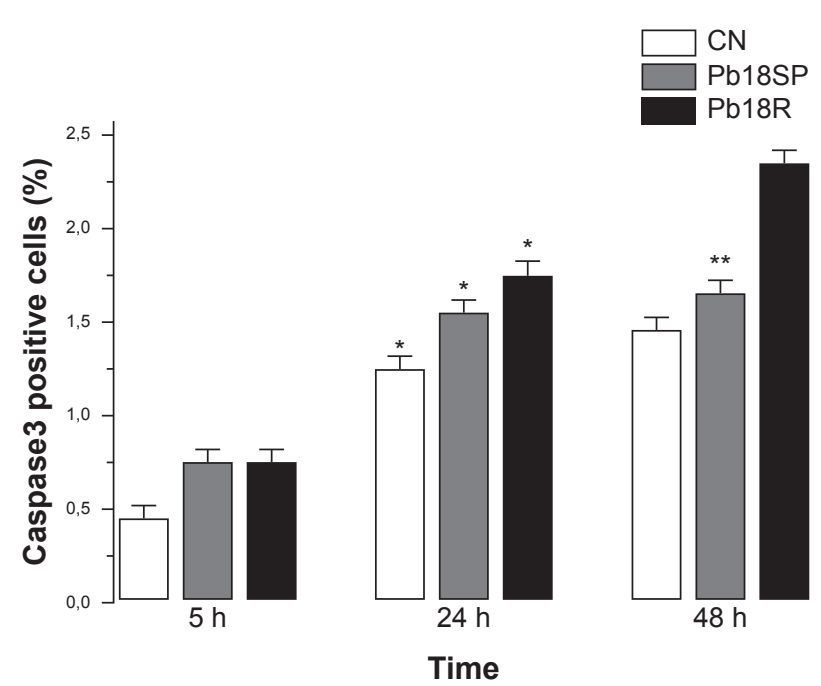

Fig. 4: the expression caspase-3 protein in A549 cells. Following treatment with Paracoccidioides brasiliensis for the time periods indicate, cells were collected. Caspase-3 proteins were detected by flow cytometry. Pb18SP: strain 18 of P. brasiliensis; Pb18R: strain 18 of $P$. brasiliensis recently isolated from cell culture; $\mathrm{CN}$ : cells not infected; *: not significant; **: $\mathrm{p}<0.05$ compared Pb18SP with $\mathrm{Pb} 18 \mathrm{R}$ in $48 \mathrm{~h}$. Values given are mean \pm standard deviation of three independent experiments.

recovering some of the virulence factors (Brummer et al. 1990, Andreotti et al. 2005). Although, this subject has already been discussed in the literature, few studies have identified the factors involved in the loss of virulence. As demonstrated in our previous study, a $30-\mathrm{kDa}$ protein could be one factor involved in the different pattern of adhesion between the two Pb18 samples (Andreotti et al. 2005). $\mathrm{Pb} 18$ is considered more pathogenic to animals and shows greater adhesion to epithelial cells. After subculturing several times, Pb18 loses the ability to adhere, which is associated with virulence and the ability of $P$. brasiliensis to infect cells. Samples recently isolated from animals and from cell culture have recovered the ability to bind and invade epithelial cells (Andreotti et al. 2005).

The present study compares two samples of P. brasiliensis, one subcultured in vitro (18SP) and the other recently recovered from cell culture (18R), with respect to their ability to infect epithelial cells. Moreover, we demonstrate the capacity of both samples to induce apoptosis in A549 cells using the TUNEL technique and flow cytometry, evaluating DNA fragmentation and Bak, Bcl-2 and caspase 3 expression, respectively.

Two major cell types, Type I and Type II, are found in the pulmonary epithelium. Approximately $96 \%$ of the pulmonary epithelium surface area is covered by Type I cells, which are unable to divide (Ryan et al. 1994). Although Type II cells only cover a small portion of the surface area of the alveolus, they are more numerous and have distinct functions. Type II cells are also believed to be the progenitor cells for Type I pulmonary epithelial cells. Additionally, the endocytic properties of Type II cells have been well characterised (Foster et al. 1998).

Our results show that the two $P$. brasiliensis samples have distinct efficiencies for infecting A549 cells. Pb18R 
demonstrated a greater ability to infect these cells than $\mathrm{Pb} 18 \mathrm{SP}$, suggesting a change in fungal virulence after passage through cell culture, as demonstrated in previous studies (Andreotti et al. 2005). Using the TUNEL technique with a fluorescent probe (Zychlinsky \& Sansonetti 1997), we demonstrated that few apoptotic cells were detected at an early time of infection $(5 \mathrm{~h})$. However, at later time points ( 24 and $48 \mathrm{~h}$ ), a significant amount of apoptosis was observed, resulting in usual nuclear apoptotic forms (apoptotic bodies). Therefore, the modulation of apoptosis was dependent on the sample and the duration of $P$. brasiliensis infection. The expression of the anti-apoptotic protein Bcl-2 was evident in both types of infected cells at early times during the infection, but was significantly higher in Pb18R-infected cells. This result demonstrates that $P$. brasiliensis samples that had been passaged through cell culture had more prominent antiapoptotic signals. The more virulent sample (Pb18R) apparently yielded higher anti-apoptotic (Bcl-2) and pro-apoptotic (Bak) signals at 5 and $18 \mathrm{~h}$. However, a significantly low level of expression was observed for both proteins after $24 \mathrm{~h}$. Apparently, the pathways were simultaneously activated at the onset of infection, but at different intensities. In addition, the low level of Bcl-2 expression and high level of Bak expression (18 and $24 \mathrm{~h}$ ) may indicate that the more virulent sample triggers intrinsic apoptotic signals.

Bcl-2 acts by suppressing both caspase-dependent and caspase-independent pathways of apoptosis (Monney et al. 1998, Okuno et al. 1998, Cosulich et al. 1999). Considering that caspase-dependent and caspase-independent pathways could drive the cells to apoptosis, the role of caspase-3 in the apoptosis of $P$. brasiliensis-infected A549 epithelial cells was investigated. Caspases are critical mediators of classical apoptosis. Cytochrome c release leads to the activation of the initiator caspase 9 (Li et al. 1997) and this in turn activates the effector caspase 3 which is responsible for many of the morphological and biochemical features of apoptosis ( $\mathrm{Li}$ et al. 1997, Los et al. 1999). Caspase 3, the main effector caspase, is specifically required for the DNA fragmentation that results in the typical apoptotic pattern of DNA laddering. Our results demonstrate for the first time that P. brasiliensis induces caspase-dependent cell signals in A549 cells, resulting in an elevation of caspase 3 . After $48 \mathrm{~h}$ of infection with $P$. brasiliensis, these cells showed a remarkable increase in caspase 3 expression, especially in cells infected with Pb18R. Therefore, the activity of caspase 3 in these cells after $P$. brasiliensis infection shows a time-dependent regulation. Moreover, the kinetics of caspase 3 activation correlated with $P$. brasiliensis-induced DNA fragmentation. The activation of caspase 3 indicated that the lung epithelial cell injury induced by this fungus somehow triggers late apoptotic signals, such as DNA fragmentation. Pb18R induces a higher caspase 3 -activation signal, suggesting that the expression and/ or the export of the apoptosis-inducing factor(s) could be regulated by the virulence of $P$. brasiliensis. This is the first description of the association between caspase 3 activation and DNA fragmentation in this infection model by the pathogen $P$. brasiliensis. Together, our findings demonstrate that $P$. brasiliensis induces apoptosis mediated by Bcl-2, Bak, caspase-3 in A549 epithelial cells and results in DNA fragmentation. However, we know that the overall mechanism is likely a much more complex process, which may involve other apoptotic mediators and several signal transduction pathways.

Comparing two samples of $P$. brasiliensis with different virulence levels and the way they affect host cells is important for a better understanding of the pathogenesis and for the future development of new strategies to overcome this fungal infection. Recently, several genes involved in the induction of macrophage apoptosis have been found to be up regulated by $P$. brasiliensis at 24 $\mathrm{h}$ of infection, including caspases 2,8 and 3 , as well as the genes encoding caspase inhibitor 8 and Fas inhibitor (Silva et al. 2008). Induction of apoptosis by microorganisms may allow for evasion of the macrophage response. During the early phase of experimental PCM, the induction of apoptosis could be an efficient method to eliminate the fungus without causing tissue damage (Verícimo et al. 2006). On the other hand, the mechanisms of invasion and the persistence in the host cell, which subsequently induce apoptosis, may contribute to the success of $P$. brasiliensis in establishing itself in host tissues and/ or to its systemic dissemination. Therefore, further studies should focus on understanding the interaction between $P$. brasiliensis and the upstream signal transduction pathways of epithelial cells, including the apoptotic pathway, as well as understanding the exact mechanism(s) and protein(s) involved in the apoptotic pathway.

\section{REFERENCES}

Adams JM, Cory S 1998. The Bcl-2 protein family: arbiters of cell survival. Science 281: 1322-1326.

Andreotti PF, Monteiro da Silva JL, Bailao AM, Soares CMA, Benard G, Soares CP, Mendes Giannini MJS 2005. Isolation and partial characterization of a $30 \mathrm{kDa}$ adhesin from Paracoccidioides brasiliensis. Micr Infect 7: 875-881.

Brummer E, Restrepo A, Hanson LH, Stevens DA 1990. Virulence of Paracoccidioides brasiliensis: the influence of in vitro passage and storage. Mycopathologia 109: 13-18.

Cacere CR, Romano CC, Mendes Giannini MJ, Duarte AJ, Benard G 2002. The role of apoptosis in the antigen-specific T cell hyporesponsiveness of paracoccidioidomycosis patients. Clin Immunol 105: 215-222.

Campanelli AP, Martins GA, Souto JT, Pereira MS, Livonesi MC, Martinez R, Silva JS 2003. Fas-Fas ligand (CD95-CD95L) and cytotoxic T lymphocyte antigen-4 engagement mediate $\mathrm{T}$ cell unresponsiveness in patients with paracoccidioidomycosis. J Infect Dis 187: 1496-1505.

Castaneda E, Brummer E, Pappagianis D, Stevens DA 1987. Chronic pulmonary and disseminated paracocidioidomycosis in mice: quantitation of progression and chronicity. $\mathrm{J} \mathrm{Med} \mathrm{Vet}$ Mycol 23: 377-387.

Cosulich SC, Savory PJ, Clarke PR 1999. Bcl-2 regulates amplification of caspase activation by cytochrome c. Curr Biol 9: 147-150.

Foster KA, Oster CG, Mayer MM, Avery ML, Audus KL 1998. Characterization of the A549 cell line as a type II pulmonary epithelial cell model for drug metabolism. Exp Cell Res 243: 359-366.

Franco M, Lacaz CS, Restrepo-Moreno A, Del Negro G 1994. Paracoccidioidomycosis, CRC press, Boca Raton, 410 pp. 
Gavrieli Y, Sherman Y, Ben-Sasson SA 1992. Identification of programmed cell death in situ via specific labeling of nuclear DNA fragmentation. J Cell Biol 119: 493-501.

Hanna SA, Monteiro da Silva JL, Mendes Giannini MJS 2000. Adherence and intracellular parasitism of Paracoccidioides brasiliensis in Vero cells. Microb Infect 2: 1-8.

Li P, Nijhawan D, Budihardjo I, Srinivasula SM, Ahmad M, Alnemri ES, Wang X 1997. Cytochrome c and dATP-dependent formation of Apaf-1/caspase-9 complex initiates an apoptotic protease cascade. Cell 91: 479-489.

Los M, Wesselborg S, Schulze-Osthoff K 1999. The role of caspases in development, immunity and apoptotic signal transduction: lessons from knockout mice. Immunity 10: 629-639.

Macoris SA, Sugizaki MF, Peraçoli MT, Bosco SM, Hebeler-Barbosa F, Simões LB, Theodoro RC, Trinca LA, Bagagli E 2006. Virulence attenuation and phenotypic variation of Paracoccidioides brasiliensis isolates obtained from armadillos and patients. Mem Inst Oswaldo Cruz 101: 331-334.

Mendes-Giannini MJ, Hanna SA, da Silva JL, Andreotti PF, Vincenzi LR, Benard G, Lenzi HL, Soares CP 2004. Invasion of epithelial mammalian cells by Paracoccidioides brasiliensis leads to cytoskeletal rearrangement and apoptosis of the host cell. Microbes Infect 6: 882-891.

Mendes-Giannini MJ, Monteiro da Silva JL, da Silva Jf, Donofrio FC, Miranda ET, Andreotti PF, Soares CP 2008. Interactions of Paracoccidioides brasiliensis with host cells: recent advances. Mycopathologia 165: 237-248.

Mendes-Giannini MJ, Ricci LC, Uemura MA, Toscano E, Arns CW 1994. Infection and apparent invasion of Vero cells by Paracoccidioides brasiliensis. J Med Vet Mycol 32: 189-197.

Mendes-Giannini MJ, Soares CP, da Silva JL, Andreotti PF 2005. Interaction of pathogenic fungi with host cells: molecular and cellular approaches. FEMS Immunol Med Microbiol 45: 383-394.

Mendes-Giannini MJ, Taylor ML, Bouchara JB, Burger E, Calich VL, Escalante ED, Hanna SA, Lenzi HL, Machado MP, Miyaji M, Monteiro Da Silva JL, Mota EM, Restrepo A, Restrepo S, Tronchin G, Vincenzi LR, Xidieh CF, Zenteno E 2000. Pathogenesis II: fungal responses to host responses: interaction of host cells with fungi. Med Mycol 1: 113-123.

Monney L, Otter I, Olivier R, Ozer HL, Haas AL, Omura S, Borner C 1998. Defects in the ubiquitin pathway induce caspase independent apoptosis blocked by Bcl-2. J Biol Chem 273: 6121-6131.
Monteiro da Silva JL, Andreotti PF, Benard G, Soares CP, Miranda ET, Mendes-Giannini MJ 2007. Epithelial cells treated with genistein inhibit adhesion and endocytosis of Paracoccidioides brasiliensis. Antonie Van Leeuwenhoek 92: 129-135.

Moss JE, Aliprantis AO, Zychlinsky A 1999. The regulation of apoptosis by microbial pathogens. Int Rev Cytol 187: 203-259.

Perskvist N, Long M, Stendahl O, Zheng L 2002. Mycobacterium tuberculosis promotes apoptosis in human neutrophils by activating caspase- 3 and altering expression of $\mathrm{Bax} / \mathrm{Bcl}-\mathrm{xL}$ via an oxygen-dependent pathway. J Immunol 168: 6358-6365.

Okuno S, Shimizu S, Ito T, Nomura M, Hamada E, Tsujimoto Y, Matsuda H 1998. Bcl-2 prevents caspase-independent cell death. J Biol Chem 273: 34272-34277.

Ryan RM, Mineo-Kuhn MM, Kramer CM, Finkel-stein JN 1994. Growth factors alter neonatal type II alveolar epithelial cell proliferation. Am J Physiol 266: 17-22.

San-Blas G, San-Blas F, Ormaechea E, Serrano LE 1977. Cell wall analysis of adenine requiring mutant of the yeast like form of Paracoccidioides brasiliensis strain IVICPb9. Sabouraudia 15: 297-303.

Shimizu S, Narita M, Tsujimoto Y 1999. Bcl-2 family proteins regulate the release of apoptogenic cytochrome $\mathrm{c}$ by the mitochondrial channel VDAC. Nature 399: 483-487.

Silva SS, Tavares AH, Passos-Silva DG, Fachin AL, Teixeira SM, Soares CM, Carvalho MJ, Bocca AL, Silva-Pereira I, Passos GA, Felipe MS 2008. Transcriptional response of murine macrophages upon infection with opsonized Paracoccidioides brasiliensis yeast cells. Microbes Infect 10: 12-20.

Souto PC, Brito VN, Gameiro J, da Cruz-Höfling MA, Verinaud L 2003. Programmed cell death in thymus during experimental paracoccidioidomycosis. Med Microbiol Immunol 192: 225-229.

Thompson CB 1995. Apoptosis in the pathogenesis and treatment of disease. Science 267: 1456-1462.

Verícimo MA, França KM, Arnholdt AC, Kipnis TL 2006. Increased apoptosis during the early phase of experimental paracoccidioidomycosis as a phenotypic marker of resistance. Microbes Infect 8: $2811-2820$

Zychlinsky A, Sansonetti P 1997. Perspectives series: host/pathogen interactions. Apoptosis in bacterial pathogenesis. J Clin Invest 100: 493-495. 